Number of Words (abstract through to references) $=8,616$

Number of Tables $=4$

Number of Figures $=2$

$11^{\text {th }}$ February 2019

\title{
Internet-delivered cognitive behavioural therapy for perfectionism: targeting dysmorphic concern
}

\author{
Shevaugn Johnson ${ }^{1}$ \\ Sarah J. Egan, Ph.D. ${ }^{2}$ \\ Gerhard Andersson, Ph.D. ${ }^{3,4}$ \\ Per Carlbring, Ph.D. ${ }^{5,6}$ \\ Roz Shafran, DPhil ${ }^{7}$ \\ Tracey D. Wade, Ph.D. ${ }^{1}$ \\ ${ }^{1}$ School of Psychology, Flinders University, Adelaide, Australia \\ ${ }^{2}$ School of Psychology and Speech Pathology, Curtin University, Perth, Australia \\ ${ }^{3}$ Department of Behavioural Sciences and Learning, Linköping University, Linköping, Sweden \\ ${ }^{4}$ Department of Clinical Neuroscience, Karolinska Institutet, Stockholm, Sweden \\ ${ }^{5}$ Department of Psychology, Stockholm University, Stockholm, Sweden \\ ${ }^{6}$ Department of Psychology, University of Southern Denmark, Denmark \\ ${ }^{7}$ Institute of Child Health, University College of London, London, England
}

Address correspondence to: Shevaugn Johnson, School of Psychology, Flinders University, GPO Box 2100, Adelaide, South Australia, 5001, Australia; Phone +61-8-8201XXXX; Fax: +61-8-8201-3877; Email: shevuagn.johnson@flinders.edu.au

Submitted to: Body Image 


\begin{abstract}
Perfectionism is an important transdiagnostic risk factor for several psychopathologies. As such, treatments targeting perfectionism have gained increased attention over recent years. While perfectionism is postulated to be an important underlying mechanism for dysmorphic concern, no research has explored the benefits of targeting perfectionism to reduce dysmorphic concern. The current study evaluated the use of internet-delivered cognitive behavioural therapy for perfectionism (ICBT-P) with thirty-one participants (28 women) with high levels of dysmorphic concern to examine the impact on perfectionism, dysmorphic concern, body image disturbance, negative affect, and a dot-probe task assessing selective attention to appearance-based stimuli. Using a case series design, observations were collected at baseline, at the end of a four-week pre-treatment phase, after the eight-week ICBT-P, and one-month post-treatment. Intent-to-treat analyses showed significant improvement from baseline to end-of-treatment and follow-up on most of the variables, with a large effect size decrease in dysmorphic concern, and decreased vigilance for the BDD-body, BDD-positive, and BDD-negative words. The results of this study support the use of ICBT-P as an efficacious treatment worthy of further examination in populations who experience high levels of dysmorphic concern.
\end{abstract}

Keywords: dysmorphic concern; cognitive-behavioral therapy; internet; perfectionism; selective attention 


\section{Introduction}

Dysmorphic concern (DC), characterised by the overconcern with appearance-based imperfections accompanied by compulsions such as mirror checking or reassurance-seeking and associated with impairment in functioning (Castle, Molton, Preston, \& Phillips, 2004; Senín-Calderón et al., 2017), ranges from 30-46\% in young adults (Cunningham, Griffiths, Baillie, \& Murray, 2016). It is a continuous construct relevant across several disorders, including depression, anxiety, eating disorders, and body dysmorphic disorder (BDD; Castle et al., 2004; Jorgensen, Castle, Roberts, \& Groth-Marnat, 2001; Monzani et al., 2012; Oosthuizen, Lambert, \& Castle, 1998). Body image disturbance, or the distortion in perceptual and attitudinal views concerning some aspect of appearance (Cash, Melnyk, \& Hrabosky, 2004), is a particularly important aspect of DC (Jorgensen et al., 2001). It has been postulated that DC exists along the obsessive-compulsive spectrum, with BDD at the extreme end (Littleton, Axsom, \& Pury, 2005; Senín-Calderón et al., 2017). While symptoms of DC, such as body checking and reassurance-seeking, are often similar in BDD and eating disorders (Rosen \& Ramirez, 1998), some distinctions can be made, such as the propensity of individuals with BDD to endorse fewer weight, shape, and diet preoccupations (Fang \& Wilhelm, 2015). Additionally, DC in individuals with anorexia nervosa has also been associated with the overestimation of body size, a feature not reported in the BDD literature (Beilharz et al., 2019). There is limited research investigating DC psychopathology consistent with BDD (e.g., a greater propensity to focus on facial features; Fang \& Wilhelm, 2015), with a greater focus on eating disorders (Bartsch, 2007). Thus, given that DC is a trait common across a multitude of disorders and increases the risk for clinical diagnoses in populations experiencing body image disturbance (Monzani et al., 2012), targeting DC and the risk factors underlying this trait might serve to prevent clinical onset.

\subsection{Perfectionism and selective attention as risk factors for DC}

Identifying and investigating transdiagnostic risk factors has gained traction over recent years (Craske, 2012). A strength to this approach is that it addresses the overlap that occurs across disorders with similar psychopathological mechanisms (Egan, Wade, \& Shafran, 2011), and thus may lead to more effective treatment when targeted in an intervention. One postulated transdiagnostic factor is perfectionism, which has been linked to eating disorders, high degrees of body dissatisfaction, obsessive-compulsive disorder (OCD), and BDD (Egan et al., 2011; Fang \& Wilhelm, 2015; Limburg, Watson, Hagger, \& Egan, 2017). Treating perfectionism not only leads to large reductions in perfectionism but also moderate decreases in depression and anxiety (Lloyd, Schmidt, 
Khondoker, \& Tchanturia, 2015). Wilhelm's (2006) model of BDD postulates that hyper-fixations on perceived appearance flaws are maintained by rigid perfectionistic standards of beauty, ultimately triggering compulsions directed at "correcting" the imperfections.

Research in BDD populations has produced mixed results concerning the most pertinent subtypes of perfectionism. One study (Hartmann, Thomas, Greenberg, Matheny, and Wilhelm, 2015a) showed people with BDD endorsed higher perfectionistic strivings (high personal standards) than controls but not perfectionistic concerns (concerns over mistakes and perceived failures), but another study found a BDD group endorsed both perfectionistic strivings and concerns (Buhlmann, Etcoff, \& Wilhelm, 2008). This latter finding is consistent with the meta-analysis by Limburg et al. (2017) who found both subtypes of perfectionism to be transdiagnostic risk factors. In non-clinical populations perfectionism is a risk factor for DC (Bartsch, 2007; Cunningham et al., 2016; Hanstock \& O’Mahony, 2002; Kuennen \& Waldron, 2007), suggesting that perfectionism precedes the onset of clinical disorders, such as BDD. To date, no DC research has concurrently investigated the role of perfectionistic strivings and concerns in predicting and maintaining psychopathology. This is surprising, given that these subtypes of perfectionism load highly onto perfectionistic detail-oriented checking (Stairs, Smith, Zapolski, Combs, \& Settles, 2012), a postulated central feature of DC. Thus, while perfectionism appears to play an important role in maintaining symptoms across several psychological disorders, differences in pathology might be influenced by where attention is directed. For example, an individual with BDD might direct attention towards a specific facial feature, whereas an individual with OCD might be more likely to direct attention toward signals in the environment indicating contamination.

Selective attention is also an important underlying cognitive mechanism that maintains a broad array of psychopathology (Bar-Haim et al., 2007; Brooks, Prince, Stahl, Campbell, \& Treasure, 2011; Fang \& Wilhelm, 2015; Johnson, Williamson, \& Wade, 2018), and has been found to be an important risk factor for the development of DC (Onden-Lim, Wu, \& Grisham, 2012), including men at high risk of muscle dysmorphia (Jin et al., 2018). A recent meta-analysis (Johnson et al., 2018) found selective attention produced the largest effect size difference between BDD and control groups relative to central coherence, interpretive biases, and memory deficits. Consequently, these results suggest that individuals with high degrees of DC have a propensity to focus their attention toward perceived environmental threats, processes that can be targeted in therapy.

It has been postulated that the cognitive mechanisms underlying perfectionism include selective attention biases toward environmental threats signalling failure, while attention is directed away from achievements (Shafran, 
Cooper, \& Fairburn, 2002). Although cognitive-behavioural therapy (CBT) treatment models for perfectionism denote the importance of targeting maladaptive selective attentional processes (Howell et al., 2016), to date, there remains limited research testing the relationship between selective attention and perfectionism. While correlational research has shown a relationship between these constructs (Lundh \& Öst, 1996), studies using cognitive tasks have produced mixed results, with one study detecting a significant relationship between high perfectionism scores and attention bias for perfectionistic-relevant stimuli (Howell et al., 2016) and another study failing to corroborate these results (Kobori \& Tanno, 2012). Consequently, more research is needed to clarify the relationship between selective attention and perfectionism.

\subsection{CBT for Perfectionism}

CBT for perfectionism (CBT-P) reduces not only the primary outcome of perfectionism but also secondary outcomes such as depression and anxiety (Lloyd et al., 2015). To date, however, no research has examined the impact on other secondary outcomes such as DC and body image disturbance, despite the increasing evidence for the role of perfectionism in predicting and maintaining symptoms of DC and BDD (Bartsch, 2007; Cunningham et al., 2016; Hanstock \& O’Mahony, 2002; Kuennen \& Waldron, 2007; Fang \& Wilhelm, 2015). While one study has looked at CBT-P with BDD participants (Glover, Brown, Fairburn, \& Shafran, 2007), only two individuals in the sample had comorbid diagnoses of BDD (R. Shafran, personal communication, February 20, 2018). Although the researchers found significant differences between the treatment and control groups, they did not consider improvements to BDD symptomology.

Internet-delivered CBT (ICBT) has gained increased attention over recent years as a more accessible and lower cost alternative to CBT (Andersson, Titov, Dear, Rozental, \& Carlbring, 2019). A 2018 meta-analysis by Carlbring, Andersson, Cuijpers, Riper, and Hedman-Lagerlöf compared the efficacy of therapist-guided ICBT against face-to-face CBT in treating a variety of mental health conditions, including body dissatisfaction, and concluded that ICBT was as effective as the face-to-face delivery method. In addition, ICBT has been found to work for BDD and eating disorders. A 2014 meta-analysis on the efficacy of E-therapy (online and app delivery methods) showed some support for prevention, treatment, and relapse prevention in eating disorders (Loucas et al., 2014). Additionally, a randomised controlled trial (RCT) conducted in a BDD population found that compared to supportive therapy, BDD-NET produced greater reductions in BDD symptom severity and secondary treatments gains on measures of depression, global functioning, and quality of life (Enander et al., 2016). Moreover, ICBT for 
perfectionism (ICBT-P) has produced clinically significant reductions in symptoms of perfectionism, and improvements to symptoms of anxiety and depression (Arpin-Cribbie, Irvine, \& Ritvo, 2012; Egan et al., 2014; Radhu, Daskalakis, Arpin-Cribbie, Irvine, \& Ritvo, 2012; Rozental et al., 2017; Shafran et al., 2017). ICBT has also been found to have enduring effects for a multitude of psychological disorders, such as OCD and depression (Andersson, Rozental, Shafran, \& Carlbring, 2017).

\subsection{Aims and hypotheses}

Given the postulated association between perfectionism and DC, and the gap in the literature assessing the impact of perfectionism on targeting symptoms of DC, the current study sought to evaluate the use of ICBT-P with respect to our primary outcomes, perfectionistic strivings and concerns, as well as our secondary outcomes, DC, body image disturbance, selective attention biases, and indicators of negative affect including depression, anxiety, and stress, using a case series design. Given that selective attention biases are also a risk factor for DC, we predicted that targeting perfectionism would also lead to a reduction in selective attention biases for BDD-target word information. We hypothesised that compared to the baseline period, participants would show significant reductions in perfectionism (i.e., strivings and concerns) at the end-of-treatment, which would be maintained at one-month follow-up. Further, we predicted that compared to the baseline period, participants would also demonstrate significant treatment gains for all secondary outcomes at the end-of-treatment, which would be maintained at onemonth follow-up.

\section{Methods}

\subsection{Participants}

Thirty-one participants (28 women) aged eighteen to thirty-nine with a mean age of 22.06 (5.54) years and mean BMI of 25.39 ( $\mathrm{SD}=6.79$ ) were recruited between August 2017 and March 2018 using an undergraduate university participation system and flyers posted at the university. Seventy-seven percent of the sample identified as Caucasian, $10 \%$ identified as Asian, 3\% identified as African, and the remaining 10\% identified as a race not otherwise listed. Furthermore, depression (35\%) and anxiety (42\%) were the most pervasive mental health problems endorsed by participants and the most commonly reported family mental health conditions (52\% and 32\% respectively). All participants gave informed consent electronically prior to commencing the study and were compensated $\$ 45$ to take part in the entire study. This project was approved by the Social and Behavioural Research Ethics Committee (approval code 140.17). The following inclusion criteria were assessed using a single response option: i) spoke English as preferred 
language, ii) were not dependent on illicit drugs or alcohol, iii) were not pregnant, iv) did not have visual or motor impairments v) were not actively suicidal, vi) had not been given a diagnosis of BDD, and v) had clinically significant DC (scoring >11 on the Dysmorphic Concern Questionnaire $\{\mathrm{DCQ}\}$; Oosthuizen et al., 1998). To maintain a focus on DC consistent with BDD symptomology, we did not include individuals who exclusively endorsed weight concerns (Buhlmann, Reese, Renaud, \& Wilhelm, 2008; Fang \& Wilhelm, 2015). Further, given that muscle dysmorphia is a specifier of BDD and that areas above the neck are the most common preoccupations and are more prevalent in BDD than in eating disorders (Buhlmann et al., 2008; Fang \& Wilhelm, 2015), we selected only those participants who identified a preoccupation with muscle mass, head shape, skin, hair, and/or at least one facial feature. Most participants endorsed three or more preoccupations with the legs $(n=25)$, muscles $(n=21)$, and skin $(n=19)$ being the most common areas of concern.

\subsection{Design}

The current study employed a case series design where observations were collected on four occasions: at baseline (Time 1), at the end of a four-week pre-treatment phase (Time 2), at the end-of-treatment after completion of the online eight-week program (Time 3), and at one-month follow-up (Time 4). The waitlist period was included to allow us to compare within-group effect sizes to the treatment period, and a four-week period was chosen to permit some indication of stability while not requiring participants to wait the entire eight-week length of the intervention. The following precautions were taken to limit bias: clearly defined objectives and protocols, specified inclusion/exclusion criteria, predetermined study duration and follow-up periods, and valid clinical outcome measures (Chan \& Bhandari, 2011). All participants were first screened for study eligibility before undertaking an initial assessment. Assessments were completed at all time points (baseline, pre-treatment, end-of-treatment, and one-month follow-up).

\subsection{Measures}

\subsubsection{Frost Multidimensional Perfectionism Scale (FMPS)}

Only the Concern over Mistakes (i.e., perfectionistic concerns), Doubts about Actions (i.e., perfectionistic concerns), and Personal Standards (i.e., perfectionistic strivings) subscales of the FMPS (Frost, Marten, Lahart, \& Rosenblate, 1990) were used. Higher scores on each subscale indicate greater levels of perfectionism. The FMPS has been found to have good reliability and validity (Frost et al., 1990). Due to limitations with Cronbach's alpha assumptions (McNeish \& Harlow, 2018), Coefficient H was computed as an indicator of internal reliability at all time points and the values for the FMPS Concern over Mistakes, Doubts about Actions, and Personal Standards subscales ranged from $.95-.96, .83-.89$, and $.88-.93$ respectively. 


\subsubsection{Multidimensional Body Self-Relations Questionnaire-Appearance Scales (MBSRQ-AS)}

The MBSRQ-AS measures body image disturbance and comprises of thirty-four items and five appearancebased subscales (Brown, Cash, \& Mikulka, 1990): Appearance Evaluation (satisfaction with overall appearance), Appearance Orientation (preoccupation with appearance), Body Areas Satisfaction (satisfaction with specific aspects of appearance), Overweight Preoccupation (dietary restrictions and weight-based anxiety), and Selfclassified Weight (self-appraisals of weight). Higher scores on the Appearance Evaluation and Body Areas Satisfaction subscales, representing greater levels of satisfaction with overall and specific aspects of appearance, reflect lower levels of body image disturbance. On the other hand, higher scores on the Appearance Orientation and Overweight Preoccupation subscales, reflecting appearance-related and weight-based preoccupations and compulsions, indicate greater levels of body image disturbance.

The MBSRQ-AS has been reported to have good psychometric properties in both non-clinical and clinical populations endorsing symptoms of eating disorders and BDD (Hartmann et al., 2015b; Hrabosky et al., 2009; Roncero, Perpiñá, Marco, \& Sánchez-Reales, 2015; Rosen, Reiter, \& Orosan, 1995). Furthermore, the five-factor structure has been validated in non-clinical (Roncero et al., 2015) and eating disorder populations (VossbeckElsebusch et al., 2014) using Spanish and German versions of the MBSRQ-AS. However, Vossbeack-Elsebusch et al. (2014) detected strong goodness of fit indices for all the factors, except the Self-Classified Weight subscale. Based on these findings, we excluded the Self-Classified Weight subscale from the analyses. The Appearance Evaluation, Appearance Orientation, Body Areas Satisfaction, and Overweight Preoccupation subscales generated Coefficient $\mathrm{H}$ values that ranged from $.91-.97, .84-.94, .85-.91$, and $.85-.92$ respectively.

\subsubsection{Short-form version Depression Anxiety Stress Scales (DASS-21)}

Used to assess depression, anxiety, and stress, the DASS-21 is a condensed version of Lovibond and Lovibond's (1995) 42-item DASS scale and is comprised of twenty-one items. It has been reported to have good psychometric properties and factor analyses have confirmed a three-factor structure (Henry \& Crawford, 2005). This measure produced Coefficient $\mathrm{H}$ values that ranged from $.94-.97, .86-.95$, and $.89-.94$ for depression, anxiety, and stress respectively.

\subsubsection{Dysmorphic Concern Questionnaire (DCQ)}

The DCQ is thought to capture a variety of appearance-based concerns. It is comprised of seven items with higher scores indicative of greater DC. Jorgensen and colleagues (2001) concluded that the DCQ adequately 
differentiated the BDD group from other psychiatric disorders. While a variety of cut-off scores have been proposed, a cut-off score of eleven is said to have high sensitivity (89\%) and specificity (95\%) for a diagnosis of BDD (Mancuso, Knoesen, \& Castle, 2010). While other conditions (such as health anxiety) cannot be ruled out using this cut-off, earlier studies support this cut-off score as indicating significant appearance-based concerns (Stangier, Janich, Adam-Schwebe, Berger, \& Wolter, 2003; Monzani et al., 2012; Schieber, Kollei, de Zwaan, \& Martin, 2018), and using a lower value reduces the probability of false negative detection rates (Schieber et al., 2018). Therefore, in the current study, we included only those participants who scored an eleven or above on the DCQ, indicating clinically significant DCs (Monzani et al., 2012; Schieber et al., 2018). Given that we were interested primarily in DC psychopathology relevant to BDD and that factor analyses have shown it to have the lowest factor loading (Monzani et al.,2012; Schieber et al., 2018; Senín-Calderón et al., 2017), item three from the DCQ (assessing preoccupations with excessive body odour, flatulence, and sweating) was dropped from the analyses. In the current study, Coefficient $\mathrm{H}$ values ranged from .85-.98. Any participants who scored a one or above on item 1 "Have you ever been very concerned about some aspect of your physical appearance" of the DCQ administered at Time 1, were prompted to respond to the following question: "Which aspect(s) of your appearance concern you? (e.g., nose, skin, hair, muscles, etc.)". Additionally, for all DCQ measures administered following the completion of pre-treatment measures, the DCQ instructions were modified to read "Please select the number that best corresponds to your agreement with each statement below. These questions refer to your experiences over the PAST WEEK".

\subsection{5. $\quad$ Dot-probe task}

Developed by MacLeod, Mathews, and Tata (1986), the dot-probe paradigm is one of the most widely used measures of selective attention, in which attention is directed toward or away from the target stimuli. In traditional versions of the dot-probe detection task, two words are presented to opposite ends of the screen, in which one of the words is replaced by a dot. Participants are required to detect the dot as quickly as possible by pressing the corresponding key (Salemink, van den Hout, \& Kindt, 2007). Participants displaying higher degrees of psychopathology are expected to respond faster to the dots replacing the target stimuli (Salemink et al., 2007).

In the current study, after reading instructions, participants received twelve practice trials with paired neutral words. Presentation of words was made up of a size twelve Ariel font with upper- and lower-case black letters (white background), resulting in a measured font height of $18 \mathrm{~mm}$. A total of two blocks were created, with the first representing practice trials made up of city names and the other made up of two trials of object-related/buffer words. 
Subsequently, to ensure that the same word set was not presented sequentially and that the correct response (i.e. left or right) was limited to three successive responses per block trial, 160 experimental word trials were presented randomly using an algorithm. Word pairs were presented a total of eight times with four potential word combinations repeated twice (totalling 160 experimental trials). To align participant gaze, a fixation cross was presented for 500 milliseconds (ms), followed by a blank screen presented for $200 \mathrm{~ms}$. Following the alignment of the participant gaze, a matched target and neutral word was presented on the left and right side of the screen. This was subsequently replaced with a dot that appeared on either the left or right side of the screen, prompting participants to select the corresponding right (“Z") or left (“"”) key. The word pairs and dots were presented for $500 \mathrm{~ms}$, with a fixed trial interval of $500 \mathrm{~ms}$.

Stimuli consisted of forty target words and forty matched neutral words. Four published DC and BDD studies using dot-probe and Emotional Stroop tasks were used to generate most of the stimuli selected (Buhlmann, McNally, Wilhelm, \& Florin, 2002; Onden-Lim et al., 2012; Rossell, Labuschagne, Dunai, Kyrios, \& Castle, 2014; Toh, Castle, \& Rossell, 2017). Any additional stimuli were synonyms of these words. The BDD-body word stimuli included eyebrows, nose, and teeth. The BDD-negative words included disgusting, deformity, and disfigured. The BDD-positive words included attractive, sexy, and handsome. All word types were expected to correlate positively with DC. Examples of the target and matched stimuli for each category were: eyebrows (backpack), deformity (parameter), and attractive (spectacles). All target and matched neutral words can be found in the online data repository (https://doi.org/10.6084/m9.figshare.7304216). Each trial was counterbalanced using Kucera and Francis' (1967) guide to match words for length, syllable, and frequency.

To address the limitations of multiple comparisons and the impact of task-related anxiety on disengagement from target stimuli on the dot-probe task (Frewen, Dozois, Joanisse, \& Neufeld, 2008), we chose only to analyse the orientation scores for the three-word types (i.e., BDD-body, BDD-negative, BDD-positive). Orientation scores were calculated to capture vigilance toward the three-word types. This was measured by dividing neutral trials (in neutral-neutral word pair presentations) by congruent trials (where the dot follows the target word in a neutral-target word pair presentation). A higher value indicated greater vigilance toward the target word stimuli.

\subsubsection{Intervention: Overcoming Perfectionism}

The current study used the same ICBT protocol for clinical perfectionism (Egan, Wade, Shafran, \& Antony, 2014), which has been evaluated previously (Rozental et al., 2017; Shafran et al., 2017). Overcoming Perfectionism is comprised of eight treatment modules; participants were instructed to complete the program at a 
rate of one module per week for a total of eight weeks. All information was accessed through a secure website. Content included reading material on the nature of CBT, clinical perfectionism, and factors maintaining symptomology. Further, homework assignments included behavioural experiments, cost-benefit analyses, cognitive restructuring, and graded exposure. The eight modules are outlined as follows: 1) understanding perfectionism 2) your perfectionism cycle 3) surveys and experiments 4) new ways of thinking 5) useful skills for managing unhelpful perfectionism 6) self-criticism or self-compassion? 7) re-examining the way we define our self-worth 8) staying well: managing unhelpful perfectionism in the long-term. Management of the online system was conducted by the first author. Participants were sent weekly reminder emails to complete the scheduled module one day before the due date. Before proceeding to the next module, it was ensured that each participant had completed all prior content. No further interaction with participants occurred throughout the completion of these modules.

\subsection{Procedure}

At Times 1 and 4, participants attended the university laboratory to complete the cognitive computer task and a series of online questionnaires administered on Qualtrics, which assessed levels of perfectionism, DC, body image disturbance, mood, and stress. Assessments were completed on a desktop personal computer (PC) with a twenty-two-inch monitor, a screen size of 470 x $298 \mathrm{~mm}$, and a screen resolution (pixels) of 1680 width x 1050 height x 32 depth. Completion time for the cognitive task and web-based questionnaires was twenty minutes.

All participants were required to wait four weeks before completing the pre-treatment measures at Time 2 (excluding the cognitive task), which could be completed from any PC. Completion time was approximately ten minutes. Following completion of the pre-treatment measures, participants commenced the eight-week online perfectionism program from a preferred PC. After completion of each weekly module (at a rate of one module per week, with completion times of approximately thirty minutes), participants were administered the seven-item DCQ questionnaire. Following completion of the eighth and final module (Time 3), participants were given the same measures administered at Time 2. After a one-month wait period, at Time 4, participants were asked to return to the university laboratory to complete the same cognitive computer task and baseline measures (excluding demographics) given at Time 1. Any participants who dropped out of the study after having commenced the treatment modules were given the option to wait one month from that time period and return to the lab for the final assessment.

\subsection{Data analyses}


To determine the suitability of parametric testing, normality was assessed across all time points using the Shapiro-Wilk test and visual inspection of histograms. Using all the data points from all time points as a single variable, we looked for outliers on each self-report variable of interest. Moreover, using this same method, we looked for outliers (scores deviating 3 standard deviations from the mean) on the dot-probe task. After restructuring the datasets such that all time points could be analysed as a single variable, no outliers were identified on any of the primary or secondary variables of interest.

In the current study, people who completed all treatment modules also completed all assessments, while those who did not complete all modules did not complete all assessments. The former were termed completers, and the latter were termed non-completers. Using logistic regression, comparisons were made between the two groups to ensure that data were missing at random.

To determine change over time with our treatment outcomes, multilevel modelling was employed, which uses maximum likelihood estimation to permit the inclusion of all cases with missing data into the analyses, thus representing intent-to-treat (ITT) analyses. We used a linear mixed model with fixed effects and an unstructured covariance matrix that applied a Bonferroni correction. The dependent variables represented the outcomes (i.e., perfectionism, body image disturbance, depression, anxiety, stress, and DC) at each time point analysed and the fixed variable was time. We also repeated the analyses while covarying for the effects of age (which could impact the dot-probe task) and BMI (which could impact the MBSRQ-AS or DCQ), which were entered as two additional fixed variables. To calculate within-group changes (Cohen's $d$ ) with completer and ITT samples (21 and 31 respectively), an online Psychometrica calculator (https://www.psychometrica.de/effect_size.html\#repeated) was used which corrects for correlations over time. We then examined within-group effect sizes between three time points: 1) baseline to pre-treatment 2) baseline to end-of-treatment and 3) baseline to one-month follow-up. Using the same online calculator, we computed a subset of analyses for the ITT group such that we could compare within-group effect size differences on the DCQ from baseline to modules two through seven (See Fig. 2).

\section{Results}

\subsection{Preliminary analyses}

At Time 3, the DASS-21 Depression subscale was found to be positively skewed. Further, at Time 4, both the DASS-21 Depression and Stress subscales generated positive skews. In effect, $\log 10$ transformations were computed at all DASS-21 Depression and Stress time points, resulting in normal distributions. All other variables 
were found to be normally distributed. There were no significant differences between men and women on any of the variables of interest.

\subsection{Non-completion}

In the current study, 32\% of participants were considered non-completers (see Fig. 1 for reasons for attrition). This included two participants who dropped out over the first two treatment modules, but who agreed to return to the lab one month afterward to complete the final assessment phase. Logistic regression analyses revealed that no baseline variables predicted non-completion (see Table 1).

Additionally, a subset of analyses was computed such that comparisons could be made between the completers ( $\mathrm{n}=21)$ and non-completers who finished a minimum of two treatment modules $(n=4)$. Using the Psychometrica calculator, compared to the completer group $(d=-0.78)$, reductions in DCQ scores from baseline to module two were greater in the non-completer group $(d=-6.00)$.

\subsection{Symptom change from baseline to pre-treatment period}

Only the MBSRQ-AS Overweight Preoccupation subscale showed significant differences from baseline (Time 1) to the pre-treatment phase (Time 2), whereby scores increased after the four-week wait period. There were no significant differences from the baseline to the pre-treatment phase on any of the other variables analysed (See

Table 2). No significant differences from baseline to pre-treatment were detected on any of the variables of interest when covarying for the effects of age and BMI (See Table 3). Completer analyses were also computed, which revealed a similar pattern of results.

\subsection{Symptom change from baseline to end-of-treatment and one-month follow-up}

Significant reductions in perfectionism, body image disturbance, depression, stress, and DC were demonstrated form baseline to the end-of-treatment phase; these results were maintained at one-month follow-up. A significant increase was also evident on the MBSRQ-AS Appearance Evaluation subscale from baseline to the one-month follow-up phase, which indicated a reduction in body image disturbance. For the dot-probe analyses, significant increases were evident in orientation scores for all word types (i.e., BDD-body, BDD-negative, and BDD-positive) from baseline to one-month follow-up, indicating a reduction in vigilance toward the target stimuli. This suggests that selective attention is an epiphenomenon of DC and may not require treatment with interventions such as Cognitive Bias Modification (Notebaert, Clarke, Grafton, \& Macleod, 2015). From baseline to end-of-treatment phases, effect sizes ranged from small to large on the FMPS Concerns over Mistakes, Doubts about Actions, and 
Personal Standards subscales ( $d=-0.84,-0.70,-0.37$ respectively), ranged from small to medium for the MBSRQAS Appearance Evaluation, Appearance Orientation, Body Areas Satisfaction, and Overweight Preoccupation subscales ( $d=0.47,-0.60,0.68,0.09$ respectively), ranged from small to large on the DASS-21 Anxiety, Depression, and Stress subscales $(d=-0.20,-0.65$, and -0.80 respectively), and was large for the DCQ $(d=-1.35)$.

DCQ scores were also tracked following the completion of each treatment module. Aside from the pretreatment period, compared to the baseline, there were significant reductions in DC symptomology across all time points (See Fig. 2). There was a large effect size difference $(d=-1.72)$ from baseline to one-month follow-up. Compared to the effect size difference between baseline and end-of-treatment, effect sizes increased from baseline to one-month follow-up on the Appearance Evaluation, Appearance Orientation, Body Areas Satisfaction, Depression, and Stress subscales, and DCQ. ITT analyses were also conducted while covarying for the effects of age and BMI. While the analyses produced a similar pattern of results, compared to baseline, the Personal Standards subscale became significant at the end-of-treatment and one-month follow-up, the Appearance Evaluation subscale became significant at the end-of-treatment, and the Body Areas Satisfaction and Stress subscales were no longer significant at the end-of-treatment and one-month follow-up (See Table 3). A similar pattern of results was detected in the completer analyses on all the variables of interest. All data relating to this study can be located by using the following reference: $\{$ dataset $\}$ Johnson et al., 2018.

\subsection{The impact of perfectionism on dysmorphic concern}

As a post-hoc analysis and to investigate the impact of perfectionism on DC, regression analyses were computed whereby the change in perfectionism (i.e., FMPS Concern over Mistakes, Doubts about Actions, and Personal Standards subscales) scores from baseline to end-of-treatment were entered as predictor variables and the DCQ score at the end-of-treatment or one-month follow-up was entered as the outcome variable (See Table 4). No significant associations were noted.

\section{Discussion}

This is the first study to investigate the efficacy of ICBT-P in targeting symptoms of DC and the first study to explore the transdiagnostic benefits of targeting perfectionism in this population. Except for anxiety scores, significant reductions in psychopathology were found at the end-of-treatment and maintained at one-month followup across all variables of interest. Furthermore, there were significant reductions between DCQ scores from the baseline and assessments following the completion of each treatment module. In the ITT group, effect size 
differences from baseline to end-of-treatment ranged from small to large for perfectionism, small to medium for body image disturbance, small to large for negative affect, and large for DC. From baseline to one-month follow-up, effect sizes ranged from small to large on orientation word scores. We saw no correlations between changes in perfectionism and changes in DC, which might indicate that there was an indirect effect of perfectionism (e.g., through a third variable such as body image disturbance) or that there was insufficient power to detect a direct effect. Our findings also suggest that improvements in DC can be achieved early on in therapy. It is also of interest to note that compared to the end-of-treatment phase, effect sizes were larger at one-month follow-up for many of the variables analysed. This indicated that not only did the treatment effects endure over time, but they also became larger (See Tables $\mathbf{2}$ and $\mathbf{3}$ ). Additionally, compared to the completer group, those who completed at least two treatment modules and then dropped out of the study had a much larger effect size decrease in DCs from baseline to module two, suggesting that reasons for non-completion might have also been influenced by high perceived initial benefit of the treatment program.

The results from this case series were consistent with previous ICBT-P studies (Arpin- Cribbie et al., 2012; Radhu et al., 2012; Rozental et al., 2017; Shafran et al., 2017), as well as the BDD studies (Buhlmann et al., 2008; Hartmann et a., 2015a) and meta-analytic study by Limburg and colleagues (2017), who found perfectionism to be an important underlying feature maintaining psychopathology. The results of the current study also reflect novel research findings, which indicate that targeting symptoms of perfectionism reduces vigilance toward BDD-target word stimuli relative to a wait-list period. These findings are consistent with Shafran et al. (2002) who postulate that the cognitive mechanism underlying perfectionism involves selective attention biases toward environmental threats signalling failure. In the case of individuals with clinically significant DCs, this might be reflected in attentional biases toward appearance-based stimuli. According to the BDD model by Wilhelm (2006), individuals with high degrees of DC engage in cognitive distortions whereby perceived imperfections trigger global negative selfevaluations (e.g., "if I am not attractive then I am a failure"). Similarly, in Veale's (2004) BDD model, heightened perfectionistic standards of beauty are thought to play an important role in maintaining symptoms of DC. It is of interest to note that this intervention manifested in greater improvements on the DCQ compared to the FMPS; perfection in this population may be primarily focused on appearance-based concerns.

\subsection{Limitations}

Future research is required to address the current study's limitations. First, a one-month follow-up period is 
insufficient to determine whether ICBT-P produced long-term reductions in the psychopathological mechanisms associated with DC. Second, although precautions were taken to limit study bias, the use of a case series design and the lack of a true control group increased the risk of bias and decreased generalisablity of the findings. For example, we cannot rule out the possibility that treatment effects were influenced by the passage of time and the expectation that symptoms would improve. Furthermore, due to the lack of a control group, it was not possible to ascertain whether treatment effects were a true reflection of the intervention or whether these effects were influenced by the regression towards the mean. The Medical Research Council does recommend, when developing complex interventions, the use of pilot research such as case series designs prior to the implementation of RCTs (Craig et al., 2008); these designs can be used to develop effect size changes that can be used in future power analyses. Third, although men and women did not differ on any of the variables of interest, most participants were women (90\%), which might also lower the generalisability of our findings. Fourth, to address a gap in the DC literature, specifications were put forth to recruit a population endorsing symptomology more specific to BDD. However, the DCQ captures symptomology consistent with other disorders, therefore, we cannot ascertain with certainty whether this intervention would be useful for patients with symptoms of BDD. Fifth, we did not pilot test the dot-probe stimuli or covary for the effects of intellectual quotient and education, which might have confounded the results. It is also worth noting that the $95 \%$ confidence intervals for the orientation word scores were large, indicating that there might have been issues with the reliability of the dot-probe task, a concern highlighted in earlier research (Schmukle, 2005). Finally, because this was an internet intervention, a structured clinical interview was not undertaken. In effect, we were unable to ascertain whether any of our participants met criteria for a psychiatric diagnosis. Thus, failure to include a symptom severity measure of BDD was a further limitation of the current research, as levels of symptomatology may moderate response to the ICBT-P. In effect, to improve and titrate treatment options, referrals for a more comprehensive assessment could occur prior to enrolling participants in treatment programs. While these results cannot be translated directly to BDD populations, this study was consistent with the BDD-NET findings by Enander and colleagues (2016) and conformed to the 2005 NICE guidelines for BDD by trialling the use of ICBT unspecific to BDD psychopathology in a DC population. Better powered studies are required to test models that can explain how perfectionism impacts our secondary outcomes.

\subsection{Future directions}

The results of this case series might be used to inform the development of future dot-probe stimuli. For 
example, researchers might consider incorporating stimuli depicting asymmetrical facial features. Testing this in populations with clinically significant DCs can provide valuable insight into the aetiology of clinical disorders. Given that reliability of the dot-probe task has been called into question (Schmukle, 2005), to bolster reliability, future research might consider winsorizing outliers in replace of using pre-determined standard deviation cut-off scores (Price et al., 2015). Nevertheless, targeting general symptoms of perfectionism led to a reduction in vigilance toward the BDD-target word stimuli. Thus, future research might consider replicating this study in a clinical population with BDD. It might also be of interest to explore the transdiagnostic benefits of perfectionism treatment programs in other psychiatric populations known to display selective attention abnormalities, such as social phobia and eating disorders (Brooks et al., 2011; Yair, Lamy, Pergamin, Bakermans-Kranenburg, \& Van Ijzendoorn, 2007). Furthermore, given that participants improved on measures of perfectionistic strivings and concerns, future DC research should endeavour to replicate these results, such that a more comprehensive understanding of the specific subtypes of perfectionism underlying DC can be achieved.

While more research is needed to replicate these findings, these results provide important insights into the development of novel CBT-based approaches. For example, for the purposes of DC research, it might useful to modify the current intervention program to include material that is specific to appearance-related imperfections. Finally, these preliminary results suggest that future DC research should be carried out to evaluate the efficacy of CBT-P against disorder-specific CBT-based approaches, such as CBT-BDD (Rosen et al., 1995), using an RCT design (NICE, 2005). Given the treatment barriers common in populations with high levels of DCs (e.g., shame, poor screening practices, misdiagnoses, and access issues; Buhlmann \& Winter, 2011), exploring options outside the context of intensive, specialised approaches, such as CBT-BDD (Harrison et al., 2016), would be fruitful. 


\section{Acknowledgements}

The authors thank Paul Douglas from Flinders University for his assistance with the design and execution of the dotprobe task.

\section{Funding}

This research did not receive any specific grant from funding agencies in the public, commercial, or not-forprofit sectors. 


\section{References}

Andersson, G., Rozental, A., Shafran, R., \& Carlbring, P. (2018). Long-term effects of internet-supported cognitive behaviour therapy. Expert Review of Neurotherapeutics, 18, 21-28. https://doi.org/10.1080/14737175.2018.1400381

Andersson, G., Titov, N., Dear, B. F., Rozental, A., \& Carlbring, P. (2019). Internet-delivered psychological treatments: from innovation to implementation. World Psychiatry, 18, 20-28. https://doi.org/10.1002/wps.20610

Arpin-Cribbie, C., Irvine, J., \& Ritvo, P. (2012). Web-based cognitive-behavioral therapy for perfectionism: A randomized controlled trial. Psychotherapy research, 22, 194-207. https://doi.org/10.1080/10503307.2011.637242

Bar-Haim, Y., Lamy, D., Pergamin, L., Bakermans-Kranenburg, M., Van IJzendoorn, M., \& Cooper, Harris. (2007). Threat-Related Attentional Bias in Anxious and Nonanxious Individuals: A Meta-Analytic Study. Psychological Bulletin, 133, 1-24. https://doi.org/10.1037/0033-2909.133.1.1

Bartsch, D. (2007). Prevalence of body dysmorphic disorder symptoms and associated clinical features among Australian university students. Clinical Psychologist, 11, 16-23. https://doi.org/10.1080/13284200601178532

Beilharz, F., Phillipou, A., Castle, D., Jenkins, Z., Cistullo, L., \& Rossell, S. (2019). Dysmorphic concern in anorexia nervosa; implications for recovery. Psychiatry Research, 273, 657. https://doi.org/10.1016/j.psychres.2019.01.102

Brooks, S., Prince, A., Stahl, D., Campbell, I.A., \& Treasure, J. (2011). A systematic review and meta-analysis of cognitive bias to food stimuli in people with disordered eating behaviour. Clinical Psychology Review, 31, 37-51. https://doi.org/10.1016/j.cpr.2010.09.006

Brown, T. A., Cash, T. F., \& Mikulka, P. J. (1990). Attitudinal body-image assessment: Factor analysis of the BodySelf Relations Questionnaire. Journal of Personality Assessment, 55, 135-144. https://doi.org/10.1080/00223891.1990.9674053

Buhlmann, Etcoff, \& Wilhelm. (2008). Facial attractiveness ratings and perfectionism in body dysmorphic disorder and obsessive-compulsive disorder. Journal of Anxiety Disorders, 22, 540-547. https://doi.org/10.1016/j.janxdis.2007.05.004 
Buhlmann, U., McNally, R. J., Wilhelm, S., \& Florin, I. (2002). Selective processing of emotional information in body dysmorphic disorder. Journal of Anxiety Disorders, 16, 289-298. https://doi.org/10.1016/S08876185(02)00100-7

Buhlmann, U., Reese, H.E., Renaud, S., Wilhelm, S. (2008). Clinical considerations for the treatment of body dysmorphic disorder with cognitive-behavioral therapy, Body Image 5, 39-49. https://doi.org/doi:10.1016/j.bodyim.2007.12.002

Buhlmann, U., \& Winter, A. (2011). Perceived ugliness: an update on treatment- relevant aspects of body dysmorphic disorder. Current Psychiatry Reports, 13, 283-288. https://doi.org/10.1007/s11920-011-0203-5

Carlbring, P., Andersson, G., Cuijpers, P., Riper, H., \& Hedman-Lagerlöf, E. (2018). Internet-based vs. face-to-face cognitive behavior therapy for psychiatric and somatic disorders: An updated systematic review and metaanalysis. Cognitive Behaviour Therapy, 47, 1-18. https://doi.org/10.1080/16506073.2017.1401115

Cash, T. F., Melnyk, S. E., \& Hrabosky, J. I. (2004). The assessment of body image investment: An extensive revision of the Appearance Schemas Inventory. International Journal of Eating Disorders, 35(3), 305-316. https://doi.org/10.1002/eat.10264

Castle, D., Molton, M., Hoffman, K., Preston, N., \& Phillips, K. (2004). Correlates of dysmorphic concern in people seeking cosmetic enhancement. Australian and New Zealand Journal of Psychiatry, 2004, Vol.38(6), P.439-444, 38, 439-444. https://doi.org/10.1080/j.1440-1614.2004.01381.x

Chan, K., \& Bhandari, M. (2011). Three-minute critical appraisal of a case series article. Indian Journal of Orthopaedics, 45, 103-104. https://doi.org/10.4103/0019-5413.77126

Cohen, B.H. (2001). Explaining Psychological Statistics. New York, NY: John Wiley \& Sons.

Craig, P., Dieppe, P., Macintyre, S., Mitchie, S., Nazareth, I., \& Petticrew, M. (2008). Developing and evaluating complex interventions: The new Medical Research Council guidance. BMJ, 337, 979-983. https://doi.org/10.1136/bmj.a1655

Craske, M.G. (2012). Transdiagnostic Treatment For Anxiety and Depression. Depression and Anxiety, 29, 749753. $10.1002 /$ da. 21992

Cuijpers, P., Donker, T., Van Straten, A., Li, J., \& Andersson, G. (2010). Is guided self-help as effective as face-toface psychotherapy for depression and anxiety disorders? A systematic review and meta-analysis of 
comparative outcome studies. Psychological Medicine, 40, 1943-1957.

https://doi.org/10.1017/S0033291710000772

Cunningham, M. L., Griffiths, S., Baillie, A., \& Murray, S. B. (2016). Emotion Dysregulation Moderates the Link Between Perfectionism and Dysmorphic Appearance Concern. Psychology of Men and Masculinity, 19, 5968. https://doi.org/10.1037/men0000082

Egan, S., van Noort, E., Chee, A., Kane, R., Hoiles, K., Shafran, R., \& Wade, T.A. (2014). Randomised controlled trial of face to face versus pure online self-help cognitive behavioural treatment for perfectionism. Behaviour Research and Therapy, 63, 107-113. https://doi.org/10.1016/j.brat.2014.09.009

Egan, S.J., Wade, T.D., \& Shafran, R. (2011). Perfectionism as a transdiagnostic process: A clinical review. Clinical Psychology Review, 31, 203-212. https://doi.org/10.1016/j.cpr.2010.04.009

Egan, S. J., Wade, T. D., Shafran, R., \& Antony, M. M. (2014). Cognitive-behavioral treatment of perfectionism. NY: Guilford.

Enander, J., Andersson, E., Mataix-Cols, D., Lichtenstein, L., Alström, K., Andersson, G., Ljótsson, B., \& Rück, C. (2016). Therapist guided internet based cognitive behavioural therapy for body dysmorphic disorder: single blind randomised controlled trial. British Medical Journal, 352, i241. https://doi.org/10.1136/bmj.i241

Fang, A., \& Wilhelm, S. (2015). Clinical features, cognitive biases, and treatment of body dysmorphic disorder. Annual review of clinical psychology, 11, 187-212. https://doi.org/10.1146/annurev-clinpsy-032814112849

Frewen, P.A., Dozois, D.J.A., Joanisse, M.F., \& Neufeld, R.W.J. (2008). Selective attention to threat versus reward: Meta-analysis and neural-network modeling of the dot-probe task. Clinical Psychology Review, 28, 307337.https://doi.org/10.1016/j.cpr.2007.05.006

Frost, R. O., Marten, P., Lahart, C., \& Rosenblate, R. (1990). The dimensions of perfectionism. Cognitive therapy and research, 14, 449-468.

Glover, D., Brown, G., Fairburn, C., \& Shafran, R. (2007). A preliminary evaluation of cognitive-behaviour therapy for clinical perfectionism: A case series. British Journal of Clinical Psychology, 46, 85-94. https://doi.org/10.1348/014466506X117388

Hanstock, T., \& O’Mahony, J. (2002). Perfectionism, acne and appearance concerns. Personality and Individual Differences, 32, 1317-1325. https://doi.org/10.1016/S0191-8869(01)00120-9 
Harrison, A., Fernández de la Cruz, L., Enander, J., Radua, J., \& Mataix-Cols,D. (2016). Cognitive-behavioral therapy for body dysmorphic disorder: A systematic review and meta-analysis of randomized controlled trials. Clinical Psychology Review,48, 43-51, https://doi.org/10.1016/j.cpr.2016.05.007

Hartmann, Thomas, Greenberg, Elliott, Matheny, \& Wilhelm. (2015b). Anorexia nervosa and body dysmorphic disorder: A comparison of body image concerns and explicit and implicit attractiveness beliefs. Body Image, 14, 77-84. https://doi.org/10.1016/j.bodyim.2015.03.013

Hartmann, A., Thomas, J., Greenberg, J., Matheny, N., \& Wilhelm, S. (2015a). Erratum. A Comparison of SelfEsteem and Perfectionism in Anorexia Nervosa and Body Dysmorphic Disorder. The Journal of Nervous and Mental Disease, 203, 484. https://doi.org/10.1097/NMD.0000000000000215

Henry, J., \& Crawford, J. (2005). The short-form version of the Depression Anxiety Stress Scales (DASS-21): Construct validity and normative data in a large non-clinical sample. British Journal of Clinical Psychology, 44, 227-239. https://doi.org/10.1348/014466505X29657

Howell, J. A., McEvoy, P. M., Grafton, B., Macleod, C., Kane, R. T., Anderson, R. A., \& Egan, S. J. (2016). Selective attention in perfectionism: Dissociating valence from perfectionism-relevance. Journal of Behavior Therapy and Experimental Psychiatry, 51, 100-108. https://doi.org/10.1016/j.jbtep.2016.01.004

Hrabosky, J.I., Cash, T.F., Veale, D., Neziroglu, F., Soll, E., Garner, D.M., . . Phillips, K.A. (2009).

Multidimensional body image comparisons among patients with eating disorders, body dysmorphic disorder, and clinical controls: A multisite study. Body Image, 6, 155-163. https://doi.org/10.1016/j.bodyim. 2009.03.001

Jin, X., Jin, Y., Zhou, S, Yand, S., Chand, S., \& Li, H. (2018). Attentional biases toward body images in males at high risk of muscle dysmorphia. PeerJ, 6, E4273. https://doi.org/10.7717/peerj.4273

[dataset] Johnson, S., Wade, T. (2018). Dysmorphic concern: Internet-delivered cognitive-behavioural therapy for perfectionism: targeting dysmorphic concern. Figshare, v1. https://figshare.com/s/e0d4a9e51b9f5b657564

Johnson, S., Williamson, P., \& Wade, T.D. (2018). A Systematic Review and Meta-analysis of Cognitive Processing Deficits Associated with Body Dysmorphic Disorder. Behaviour Research and Therapy, 107, 83-94. https://doi.org/10.1016/j.brat.2018.05.013

Jolanta, J.R.J., \& Tomasz, M.S. (2000). The links between body dysmorphic disorder and eating disorders. European Psychiatry, 15, 302-305. https://doi.org/10.1016/S0924-9338(00)00398-9 
Jorgensen, L., Castle, D., Roberts, C., \& Groth-Marnat, G. (2001). A clinical validation of the Dysmorphic Concern Questionnaire. Australian and New Zealand Journal of Psychiatry, 35, 124-128. https://doi.org/10.1046/j.1440-1614.2001.00860.x

Kobori, O., \& Tanno, Y. (2012). Self-oriented perfectionism and its relationship to selective attention: An experimental examination using social cognitive paradigm 1. Japanese Psychological Research, 54(4), 418-423. https://doi.org/10.1111/j.1468-5884.2012.00514.x

Kucera, H., \& Francis, W.N. (1967). Computational analysis of pres- ent-day English. Providence, Rl: Brown University Press.

Kuennen, M. R., \& Waldron, J. J. (2007). Relationships between specific personality traits, fat free mass indices, and the muscle dysmorphia inventory. Journal of Sport Behavior, 30, 453.

Limburg, K., Watson, H. J., Hagger, M. S., \& Egan, S. J. (2017). The relationship between perfectionism and psychopathology: A meta-analysis. Journal of Clinical Psychology, 73, 1301-1326. https://doi.org/10.1002/jclp.22435

Littleton, H.L., Axsom, D., \& Pury, C.L.S. (2005). Development of the body image concern inventory. Behaviour Research and Therapy, 43, 229-241. https://doi.org/10.1016/j.brat.2003.12.006

Lloyd, S., Schmidt, U., Khondoker, M., \& Tchanturia, K. (2015). Can psychological interventions reduce perfectionism? A systematic review and meta-analysis. Behavioural and cognitive psychotherapy, 43, 705731. https://doi.org/10.1017/S1352465814000162

Loucas, C. E., Fairburn, C. G., Whittington, C., Pennant, M. E., Stockton, S., \& Kendall, T. (2014). E-therapy in the treatment and prevention of eating disorders: A systematic review and meta-analysis. Behaviour Research and Therapy, 63C, 122-131. https://doi.org/10.1016/j.brat.2014.09.011

Lovibond, P.F., \& Lovibond, S.H. (1995). The structure of negative emotional states: Comparison of the Depression Anxiety Stress Scales (DASS) with the Beck Depression and Anxiety Inventories. Behaviour Research and Therapy, 33, 335-343. https://doi.org/10.1016/0005-7967(94)00075-U

Lundh, A., Öst, L.G. (1996). Recognition Bias for Critical Faces in Social Phobics. Behaviour Research and Therapy, 34, 787-794.

Macleod, C., Mathews, A., \& Tata, P. (1986). Attentional bias in emotional disorders. Journal of Abnormal Psychology, 95, 15-20. 
Mancuso, S. G., Knoesen, N. P., \& Castle, D. J. (2010). The Dysmorphic Concern Questionnaire: A screening measure for body dysmorphic disorder. Australian and New Zealand Journal of Psychiatry, 44, 535-542. https://doi.org/10.3109/00048671003596055

McNeish, D., \& Harlow, Lisa L. (2018). Thanks Coefficient Alpha, We’ll Take It From Here. Psychological Methods, 23, 412-433. https://doi.org/10.1037/met0000144

Monzani, B., Rijsdijk, F., Anson, M., Iervolino, A., Cherkas, L., Spector, T., \& Mataix-Cols, D. (2012). A twin study of body dysmorphic concerns. Psychological Medicine, 42, 1949-1955. https://doi.org/10.1017/S0033291711002741

NICE. (2005). Obsessive-compulsive disorder and body dysmorphic disorder: treatment. (CG31). Retrieved from https://www.nice.org.uk/guidance/cg31/chapter/4-Research-recommendations

Notebaert, L., Clarke, P.J.F., Grafton, B., \& Macleod, C. (2015). Validation of a novel attentional bias modification task: The future may be in the cards. Behaviour Research and Therapy, 65, 93-100. https://doi.org/10.1016/j.brat.2014.12.007

Onden-Lim, M., Wu, R., \& Grisham, J.R. (2012). Body image concern and selective attention to disgusting and nonself appearance-related stimuli. Body Image, 9, 535-538. https://doi.org/10.1016/j.bodyim.2012.07.005

Oosthuizen, P., Lambert, T., \& Castle, D. J. (1998). Dysmorphic concern: prevalence and associations with clinical variables. Australian and New Zealand Journal of Psychiatry, 32, 129-132. 10.1046 /j.1440$1614.1998 .00377 \mathrm{x}$

Price, R., Kuckertz, J., Siegle, G., Ladouceur, C., Silk, J., Ryan, N., . . Reynolds, Cecil R. (2015). Empirical Recommendations for Improving the Stability of the Dot-Probe Task in Clinical Research. Psychological Assessment, 27(2), 365-376. https://doi.org/10.1037/pas0000036

Radhu, N., Daskalakis, Z., Arpin-Cribbie, C., Irvine, J., Ritvo, P. (2012). Evaluating a Web-based cognitivebehavioral therapy for maladaptive perfectionism in university students. Journal of American College Health, 60, 357-366. https://doi.org/10.1080/07448481.2011.630703

Roncero, M., Perpina, C., Marco, J., \& Sanchez-Reales, S. (2015). Confirmatory factor analysis and psychometric properties of the Spanish version of the Multidimensional Body-Self Relations Questionnaire-Appearance Scales. Body Image, 14, 47. https://doi.org/10.1016/j.bodyim.2015.03.005 
Rosen, J. C., \& Ramirez, E. (1998). A comparison of eating disorders and body dysmorphic disorder on body image and psychological adjustment. Journal of Psychosomatic Research, 44, 441449.https://doi.org/10.1016/S0022-3999(97)00269-9

Rosen, J., \& Reiter, J. (1996). Development of the Body Dysmorphic Disorder Examination. Behaviour Research and Therapy, 34, 755-766. https://doi.org/10.1016/0005-7967(96)00024-1

Rosen, L. C., Reiter, J., \& Orosan, P. (1995). Cognitive-behavioural body image therapy for body dysmorphic disorder. Journal of Consulting and Clinical Psychology, 63, 263-269. http://dx.doi.org/10.1037/0022006X.63.2.263

Rossell, S. L., Labuschagne, I., Dunai, J., Kyrios, M., \& Castle, D. J. (2014). Using theories of delusion formation to explain abnormal beliefs in Body Dysmorphic Disorder (BDD). Psychiatry research, 215, 599-605. https://doi.org/10.1016/j.psychres.2013.12.030

Rozental, A., Shafran, R., Wade, T., Egan, S., Nordgren, L.B., Carlbring., P . . Andersson, G. (2017). A randomized controlled trial of Internet-Based Cognitive Behavior Therapy for perfectionism including an investigation of outcome predictors. Behaviour Research and Therapy, 95, 79-86. https://doi.org/10.1016/j.brat.2017.05.015

Salemink, E., van den Hout, M.A., \& Kindt, M. (2007). Selective attention and threat: Quick orientating versus slow disengagement and two version of the dot probe task. Behaviour Research and Therapy, 45, 607-615. https://doi.org/10.1016/j.brat.2006.04.004

Schieber, K., Kollei, I., de Zwaan, M., \& Martin, A. (2018). The Dysmorphic Concern Questionnaire in the German General Population: Psychometric Properties and Normative Data. Aesthetic Plastic Surgery, 42, 1-9. https://doi.org/10.1007/s00266-018-1183-1

Schmukle, S. (2005). Unreliability of the dot probe task. European Journal of Personality, 19, 595-605. https://doi.org/10.1002/per.554

Senín-Calderón, C., Valdés-Díaz, M., Benítez-Hernández, M.M., Núñez-Gaitán, M.C., Perona-Garcelán, S., Martínez-Cervantes, R., \& Rodríguez-Testal. J.F. (2017). Validation of Spanish Language Evaluation Instruments for Body Dysmorphic Disorder and the Dysmorphic ConcernConstruct. Frontiers in Psychology, 8, 1107. https://doi.org/10.3389/fpsyg.2017.01107 
Shafran, R., Cooper, Z., \& Fairburn, C.G. (2002). Clinical perfectionism: A cognitive-behavioural analysis. Behaviour Research and Therapy, 40, 773-791. https://doi.org/10.1016/S0005-7967(01)00059-6

Shafran, R., Wade, T.D., Egan, S.J., Kothari, R., Allcott-Watson, H., Carlbring, P . . Andersson, G. (2017). Is the devil in the detail? A randomised controlled trial of guided internet-based CBT for perfectionism. Behaviour Research and Therapy, 95, 99-106. https://doi.org/10.1016/j.brat.2017.05.014

Stairs, A.M., Smith, G.T., Zapolski, T.C.B., Combs, J.L., \& Settles, R.E. (2012). Clarifying the Construct of Perfectionism. Assessment,19, 146-166. https://doi.org/10.1177/1073191111411663

Stangier, U., Janich, C., Adam-Schwebe, S., Berger, P., \& Wolter, M. 2003. Screening for body dysmorphic disorder in dermatological outpatients. Dermatol Psychosom 4, 66- 71. https://doi.org/10.1159/000072194

Toh, W. L., Castle, D. J., \& Rossell, S. L. (2017). Attentional biases in body dysmorphic disorder (bdd): Eyetracking using the emotional Stroop task. Comprehensive Psychiatry, 74, 151-161. https://doi.org/10.1016/j.comppsych.2017.01.014

Veale, D. (2004). Advances in a cognitive behavioural model of body dysmorphic disorder. Body image, 1, 113-125. https://doi.org/10.1016/S1740-1445(03)00009-3

Vossbeck-Elsebusch, A.N., Waldorf, M., Legenbauer, T., Bauer, A., Cordes, M., \& Vocks, S. (2014). German version of the Multidimensional Body-Self Relations Questionnaire - Appearance Scales (MBSRQ-AS): Confirmatory factor analysis and validation. Body Image, 11, 191-200. https://doi.org/10.1016/j.bodyim.2014.02.002

Wilhelm, S. (2006). Feeling good about the way you look: A program for overcoming body image problems. New York, NY: Guildford Press.

Yair, B., Lamy, D., Pergamin, L., Bakermans-Kranenburg, M. J., \& Van Ijzendoorn, M. H. (2007). Threat-related attentional bias in anxious and nonanxious individuals: a meta-analytic study. Psychological Bulletin, 133, 1-24. https://doi.org/10.1037/0033-2909.133.1 


\section{Table 1}

Logistic regression analyses to assess baseline predictors of attrition.

\begin{tabular}{|c|c|c|c|c|}
\hline Variable & $\begin{array}{l}\text { Total Sample } \\
(N=31 ; M(S D) ; \\
\text { Range })\end{array}$ & $\begin{array}{l}\text { Completers } \\
(N=21 ; M(S D) ; \\
\text { Range })\end{array}$ & $\begin{array}{l}\text { Non-completers } \\
(N=10 ; M(S D) ; \\
\text { Range })\end{array}$ & $\begin{array}{l}\text { OR }(95 \%) \text { completer vs. non- } \\
\text { completer }\end{array}$ \\
\hline Age & 22.06 (5.54) 18-39 & 21.71 (5.09) 18-39 & $22.80(6.61) 18-36$ & $.97(.84: 1.10)$ \\
\hline BMI & $25.39(6.79) 16-42$ & $25.70(6.63) 16-40$ & 24.75 (7.43) $18-42$ & $1.02(.91: 1.15)$ \\
\hline FMPS CM & $32.26(7.84) 11-44$ & 33.24 (6.59)15-42 & 30.20 (10.07) 11-44 & $1.56(.65: 3.74)$ \\
\hline FMPS DA & 15.00 (2.68) 8-20 & 15.19 (2.06) 12-19 & 14.60 (3.78) 8-20 & $1.40(.44: 4.43)$ \\
\hline FMPS PS & $27.10(4.28) 18-33$ & 27.81 (4.19) 19-33 & $25.60(4.30) 18-32$ & $2.43(.65: 9.03)$ \\
\hline MBSRQ-AS AE & 13.06 (3.98) 6-20 & 13.00 (3.18) 7-18 & $13.20(5.51) 6-20$ & $.98(.31: 3.08)$ \\
\hline MBSRQ-AS AO & 46.64 (6.46) 33-60 & 45.81 (5.67) 33-54 & 48.40 (7.92) 36-60 & $.44(.10: 2.04)$ \\
\hline MBSRQ-AS BAS & $20.64(4.45) 12-31$ & $19.90(3.48) 14-28$ & $22.20(5.94) 12-31$ & $.33(.06: 1.70)$ \\
\hline MBSRQ-AS OWP & 13.90 (3.29) 6-20 & 13.86 (2.63) $10-19$ & 14.00 (4.55) 6-20 & $.95(.37: 2.40)$ \\
\hline DASS-21 Anxiety & $7.71(4.32) 1-15$ & $7.52(4.23) 1-14$ & $8.10(4.72) 1-15$ & $.80(.23: 2.78)$ \\
\hline DASS-21 Depression & $8.32(5.05) 1-18$ & $7.81(5.15) 1-18$ & $9.40(4.90) 1-17$ & $.69(.24: 1.97)$ \\
\hline DASS-21 Stress & 10.35 (4.05) 2-19 & 10.48 (4.08) 4-19 & $10.10(4.20) 2-16$ & $1.18(.31: 4.45)$ \\
\hline Orientation Body & $1.34(.44) .83-2.56$ & 1.41 (.48) .93-2.56 & $1.20(.31) .83-1.80$ & $4.16(.40: 43.26)$ \\
\hline Orientation Negative & $1.36(.44) .83-2.62$ & 1.42 (.49) .99-2.62 & $1.21(.30) 1.83-.82$ & $4.56(.39: 53.76)$ \\
\hline Orientation Positive & 1.35 (.46) .83-2.66 & 1.42 (.51) .95-2.66 & 1.19 (.29) .83-1.75 & $5.19(.42: 63.54)$ \\
\hline DCQ & $11.58(2.45) 8-18$ & 11.43 (2.69) 8-18 & $11.90(1.91) 9-15$ & . $62(.10: 3.98)$ \\
\hline
\end{tabular}

Note. BMI: Body Mass Index; FMPS, Frost Multidimensional Perfectionism Scale; FMPS CM, FMPS Concerns over Mistakes subscale; FMPS DA, FMPS Doubts about Actions subscale ; FMPS PS, FMPS Personal Standards subscale; MBSRQ-AS, Multidimensional Body-Self Relations Questionnaire-Appearance Scales; MBSRQ-AS AE, MBSRQ-AS Appearance Evaluation subscale; MBSRQ-AS AO, MBSRQ-AS Appearance Orientation subscale; MBSRQ-AS BAS, MBSRQ-AS Body Areas Satisfaction subscale; MBSRQ-AS OWP, MBSRQ-AS Overweight Preoccupation subscale; DASS21, Depression Anxiety and Stress Scale- Short Form; DASS-21Anxiety, DASS-21 Anxiety Subscale; DASS-21 Depression, DASS-21 Depression subscale; DASS-21 Stress, DASS-21 Stress subscale; Orientation Body, neutral trials (neutral-neutral word pairs)/ congruent trials for the dot-probe BDD-body word stimuli; Orientation Negative, neutral trials/ congruent trials for the dot-probe BDD-negative word stimuli; Orientation Positive, neutral trials/congruent trials for the dot-probe BDDpositive word stimuli; DCQ, Dysmorphic Concern Questionnaire. 


\section{Table 2}

Change in Outcome Variables Over Time, Using Intent-To-Treat Analyses.

\begin{tabular}{|c|c|c|c|c|c|c|c|c|c|c|c|c|c|c|c|}
\hline \multirow[b]{2}{*}{ ITT (N=31) } & \multicolumn{2}{|c|}{$\begin{array}{l}\text { Baseline } \\
\text { (Time 1) }\end{array}$} & \multicolumn{4}{|c|}{$\begin{array}{l}\text { Pre-treatment } \\
\text { (Time 2) }\end{array}$} & \multicolumn{4}{|c|}{$\begin{array}{l}\text { End-of-treatment } \\
\text { (Time 3) }\end{array}$} & \multicolumn{4}{|c|}{$\begin{array}{l}\text { One-month follow-up } \\
\text { (Time 4) }\end{array}$} & \multirow[b]{2}{*}{$\begin{array}{l}\text { Main effect of } \\
\text { Time (df), } p \text {, and } \\
\text { post-hoc comparisons }\end{array}$} \\
\hline & $\mathrm{M}^{\mathrm{a}}$ & SE & $\mathrm{M}^{\mathrm{a}}$ & SE & $\mathrm{d}$ & $95 \% \mathrm{CI}$ & $\mathrm{M}^{\mathrm{a}}$ & SE & $\mathrm{D}$ & $95 \% \mathrm{CI}$ & $\mathrm{M}^{\mathrm{a}}$ & SE & $\mathrm{d}$ & $95 \% \mathrm{CI}$ & \\
\hline FMPS CM & 3.58 & .16 & 3.61 & .15 & .05 & $-.44: .55$ & 2.85 & .18 & -.84 & $.32: 1.36$ & 2.82 & .17 & -.81 & $.29: 1.33$ & $\begin{array}{l}\mathrm{F}=7.87(3,24), .001 \\
\mathrm{~T} 1, \mathrm{~T} 2>\mathrm{T} 3, \mathrm{~T} 4\end{array}$ \\
\hline FMPS DA & 3.75 & .12 & 3.63 & .13 & -.18 & $-.68: .31$ & 3.21 & .14 & -.70 & $.18: 1.21$ & 3.28 & .14 & -.63 & $.12: .1 .14$ & $\begin{array}{l}\mathrm{F}=5.98(3,24), .003 \\
\mathrm{~T} 1, \mathrm{~T} 2>\mathrm{T} 3, \mathrm{~T} 4\end{array}$ \\
\hline FMPS PS & 3.87 & .27 & 3.73 & .28 & -.15 & $-.65: .35$ & 3.38 & .29 & -.37 & $-.87: .13$ & 3.42 & .29 & -.37 & $-.87: .14$ & $\begin{array}{l}\mathrm{F}=5.54(3,22), .01 \\
\mathrm{~T} 1, \mathrm{~T} 2>\mathrm{T} 3, \mathrm{~T} 4\end{array}$ \\
\hline $\begin{array}{l}\text { MBSRQ-AS } \\
\text { AE }\end{array}$ & 2.17 & .12 & 2.23 & .14 & .13 & $-.37: .63$ & 2.54 & .15 & .47 & $-.03: .97$ & 2.67 & .10 & .89 & $.37: 1.41$ & $\begin{array}{l}\mathrm{F}=15.64(3,26),<.001 \\
\mathrm{~T} 1, \mathrm{~T} 2<\mathrm{T} 4\end{array}$ \\
\hline $\begin{array}{l}\text { MBSRQ-AS } \\
\text { AO }\end{array}$ & 3.89 & .10 & 3.94 & .10 & .17 & $.66:-.33$ & 3.53 & .10 & -.60 & $.09: 1.11$ & 3.44 & .10 & -.81 & $.29: .1 .32$ & $\begin{array}{l}\mathrm{F}=7.78(3,24), .001 \\
\mathrm{~T} 1, \mathrm{~T} 2>\mathrm{T} 3, \mathrm{~T} 4\end{array}$ \\
\hline $\begin{array}{l}\text { MBSRQ-AS } \\
\text { BAS }\end{array}$ & 2.29 & .09 & 2.29 & .10 & .00 & $-.50: .50$ & 2.71 & .13 & .68 & $.16: 1.19$ & 2.73 & .12 & .73 & $.21: 1.24$ & $\begin{array}{l}\mathrm{F}=6.72(3,23), .002 \\
\mathrm{~T} 1, \mathrm{~T} 2<\mathrm{T} 3, \mathrm{~T} 4\end{array}$ \\
\hline $\begin{array}{l}\text { MBSRQ-AS } \\
\text { OWP }\end{array}$ & 3.48 & .15 & 3.97 & .21 & .96 & $.43: 1.48$ & 3.54 & .25 & .09 & $-.40: .59$ & 3.46 & .26 & -.03 & $-53: .46$ & $\begin{array}{l}\mathrm{F}=7.99(3,21), .001 \\
\mathrm{~T} 1<\mathrm{T} 2, \mathrm{~T} 2>\mathrm{T} 4\end{array}$ \\
\hline $\begin{array}{l}\text { DASS-21 } \\
\text { Anxiety }\end{array}$ & 1.10 & .11 & 1.14 & .12 & .07 & $-.43: .57$ & 1.00 & .15 & -.20 & $-.70: .03$ & .92 & .15 & -.32 & $-.82: .18$ & $\mathrm{~F}=1.15(3,24), .35$ \\
\hline DASS-21 & .33 & .03 & .34 & .02 & .07 & $-.43: .57$ & .24 & .03 & -.65 & $.14: 1.16$ & .23 & .03 & -.86 & $.34: 1.38$ & $\mathrm{~F}=6.72(3,23), .002$ \\
\hline
\end{tabular}


Depression $^{\mathrm{b}}$

\begin{tabular}{|c|c|c|c|c|c|c|c|c|c|c|c|c|c|c|c|}
\hline $\begin{array}{l}\text { DASS-21 } \\
\text { Stress }^{\mathrm{b}}\end{array}$ & .38 & .02 & .42 & .02 & .36 & $-.14: .86$ & .29 & .03 & -.80 & $.28: 1.32$ & .28 & .03 & -.91 & $.39: 1.44$ & $\begin{array}{l}\mathrm{F}=10.28(3,22),<.001 \\
\mathrm{~T} 1, \mathrm{~T} 2>\mathrm{T} 3, \mathrm{~T} 4\end{array}$ \\
\hline $\begin{array}{l}\text { Orientation } \\
\text { Body }\end{array}$ & 1.34 & .08 & N/A & N/A & N/A & N/A & N/A & N/A & N/A & N/A & 1.07 & .03 & .81 & $.30: 1.33$ & $\begin{array}{l}\mathrm{F}=11.11(1,30), .002 \\
\mathrm{~T} 1>\mathrm{T} 4\end{array}$ \\
\hline $\begin{array}{l}\text { Orientation } \\
\text { Negative }\end{array}$ & 1.36 & .15 & N/A & N/A & N/A & N/A & N/A & N/A & N/A & N/A & 1.09 & .13 & .35 & $-.15: .85$ & $\begin{array}{l}\mathrm{F}=10.61(1,29), .003 \\
\mathrm{~T} 1>\mathrm{T} 4\end{array}$ \\
\hline $\begin{array}{l}\text { Orientation } \\
\text { Positive }\end{array}$ & 1.35 & .08 & N/A & N/A & N/A & N/A & N/A & N/A & N/A & N/A & 1.05 & .03 & .91 & $.38: 1.43$ & $\begin{array}{l}\mathrm{F}=11.26(1,30), .002 \\
\mathrm{~T} 1>\mathrm{T} 4\end{array}$ \\
\hline DCQ & 1.93 & .07 & 1.82 & .09 & -.26 & $-.76: .24$ & 1.03 & .12 & -1.35 & $.80: 1.91$ & .90 & .12 & -1.72 & $1.14: 2.30$ & $\begin{array}{l}\mathrm{F}=21.57(3,26),<.001 \\
\mathrm{~T} 1, \mathrm{~T} 2>\mathrm{T} 3, \mathrm{~T} 4\end{array}$ \\
\hline
\end{tabular}

$\mathrm{T} 2>\mathrm{T} 3, \mathrm{~T} 4$ $\mathrm{T} 1>\mathrm{T} 4$ $\mathrm{T} 1, \mathrm{~T} 2>\mathrm{T} 3, \mathrm{~T} 4$

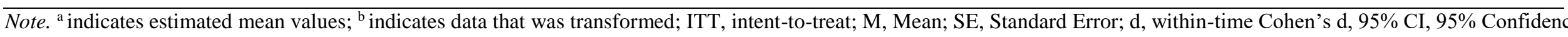
Intervals; $\mathrm{df}=$ degrees of freedom. 


\section{Table 3}

Change in Outcome Variables Over Time (Covarying for Age and BMI), Using Intent-To-Treat Analyses.

\begin{tabular}{|c|c|c|c|c|c|c|c|c|c|c|c|c|c|c|c|}
\hline \multirow[b]{2}{*}{$\operatorname{ITT}(\mathrm{N}=31)$} & \multicolumn{2}{|c|}{$\begin{array}{l}\text { Baseline } \\
\text { (Time 1) }\end{array}$} & \multicolumn{4}{|c|}{$\begin{array}{l}\text { Pre-treatment } \\
\text { (Time 2) }\end{array}$} & \multicolumn{4}{|c|}{$\begin{array}{l}\text { End-of-treatment } \\
\text { (Time 3) }\end{array}$} & \multicolumn{4}{|c|}{$\begin{array}{l}\text { One-month follow-up } \\
\text { (Time 4) }\end{array}$} & \multirow[b]{2}{*}{$\begin{array}{l}\text { Main effect of } \\
\text { time (df), } p \text {, and } \\
\text { post-hoc comparisons }\end{array}$} \\
\hline & $\mathrm{M}^{\mathrm{a}}$ & $\mathrm{SE}$ & $\mathrm{M}^{\mathrm{a}}$ & $\mathrm{SE}$ & $\mathrm{d}$ & $95 \% \mathrm{CI}$ & $\mathrm{M}^{\mathrm{a}}$ & $\mathrm{SE}$ & $\mathrm{d}$ & $95 \% \mathrm{CI}$ & $\mathrm{M}^{\mathrm{a}}$ & $\mathrm{SE}$ & $\mathrm{d}$ & $95 \% \mathrm{CI}$ & \\
\hline FMPS CM & 3.59 & .15 & 3.61 & .14 & .04 & $-.46: .54$ & 2.84 & .19 & -.92 & $.40: 1.45$ & 2.82 & .17 & -.87 & $.35: 1.40$ & $\begin{array}{l}\mathrm{F}=8.09(3,24), .001 \\
\mathrm{~T} 1, \mathrm{~T} 2>\mathrm{T} 3, \mathrm{~T} 4\end{array}$ \\
\hline FMPS DA & 3.75 & .12 & 3.63 & .13 & -.19 & $-.68: .31$ & 3.21 & .14 & -.70 & $.18: 1.21$ & 3.28 & .14 & -.63 & $.12: 1.14$ & $\begin{array}{l}\mathrm{F}=6.02(3,24), .003 \\
\mathrm{~T} 1, \mathrm{~T} 2>\mathrm{T} 3, \mathrm{~T} 4\end{array}$ \\
\hline FMPS PS & 3.87 & .11 & 3.73 & .12 & -.36 & $-.87: .14$ & 3.38 & .14 & -.90 & $.38: 1.42$ & 3.42 & .14 & -.90 & $.37: 1.42$ & $\begin{array}{l}\mathrm{F}=5.55(3,22), .005 \\
\mathrm{~T} 1, \mathrm{~T} 2>\mathrm{T} 3, \mathrm{~T} 4\end{array}$ \\
\hline $\begin{array}{l}\text { MBSRQ-AS } \\
\mathrm{AE}^{\mathrm{c}}\end{array}$ & 2.16 & .11 & 2.22 & .13 & .14 & $-.36: .64$ & 2.54 & .15 & .54 & $.03: 1.05$ & 2.67 & .09 & .99 & $.47: 1.52$ & $\begin{array}{l}\mathrm{F}=15.85(3,26),<.001 \\
\mathrm{~T} 1, \mathrm{~T} 2<\mathrm{T} 4\end{array}$ \\
\hline $\begin{array}{l}\text { MBSRQ-AS } \\
\text { AO }\end{array}$ & 3.88 & .10 & 3.94 & .09 & .20 & $-.30: .70$ & 3.54 & .10 & -.56 & $.06: 1.07$ & 3.44 & .11 & -.79 & $.27: 1.31$ & $\begin{array}{l}\mathrm{F}=7.58(3,24), .001 \\
\mathrm{~T} 1, \mathrm{~T} 2>\mathrm{T} 3, \mathrm{~T} 4\end{array}$ \\
\hline $\begin{array}{l}\text { MBSRQ-AS } \\
\text { BAS }^{\text {b }}\end{array}$ & 2.29 & .42 & 2.28 & .42 & -.00 & $-.50: .49$ & 3.59 & .43 & .45 & $-.05: .95$ & 2.74 & .42 & .16 & $-.34: .66$ & $\begin{array}{l}\mathrm{F}=20.02(3,24),<.001 \\
\mathrm{~T} 1, \mathrm{~T} 2<\mathrm{T} 3, \mathrm{~T} 4\end{array}$ \\
\hline $\begin{array}{l}\text { MBSRQ-AS } \\
\text { OWP }^{c}\end{array}$ & 3.48 & .65 & 3.57 & .65 & .04 & $-.46: .54$ & 3.50 & .69 & .01 & $-.49: .50$ & 3.43 & .69 & -.02 & $-.52: .48$ & $\mathrm{~F}=.16(3,24), .92$ \\
\hline $\begin{array}{l}\text { DASS-21 } \\
\text { Anxiety }\end{array}$ & 1.10 & .11 & 1.14 & .13 & .07 & $-.43: .57$ & 1.00 & .15 & -.20 & $-.70: .30$ & .92 & .15 & -.32 & $-.82: .18$ & $\mathrm{~F}=1.15(3,24), .35$ \\
\hline
\end{tabular}




\begin{tabular}{|c|c|c|c|c|c|c|c|c|c|c|c|c|c|c|c|}
\hline $\begin{array}{l}\text { DASS-21 } \\
\text { Depression }^{\mathrm{b}}\end{array}$ & .33 & .03 & .34 & .02 & .07 & $-.43: .57$ & .24 & .03 & -.65 & $.14: 1.16$ & .23 & .03 & -.86 & $.34: 1.38$ & $\begin{array}{l}\mathrm{F}=6.75(3,23), .002 \\
\mathrm{~T} 1>\mathrm{T} 4 \\
\mathrm{~T} 2>\mathrm{T} 3, \mathrm{~T} 4\end{array}$ \\
\hline $\begin{array}{l}\text { DASS-21 } \\
\text { Stress }^{\text {b }}\end{array}$ & .38 & .04 & .42 & .04 & .18 & $-.32: .68$ & .29 & .05 & -.40 & $-.90: .10$ & .28 & .04 & -.46 & $-.96: .05$ & $\begin{array}{l}\mathrm{F}=10.31(3,22),<.001 \\
\mathrm{~T} 1, \mathrm{~T} 2>\mathrm{T} 3, \mathrm{~T} 4,\end{array}$ \\
\hline $\begin{array}{l}\text { Orientation } \\
\text { Body }\end{array}$ & 1.34 & .08 & N/A & N/A & N/A & N/A & N/A & N/A & N/A & N/A & 1.07 & .03 & .81 & $.30: 1.33$ & $\begin{array}{l}\mathrm{F}=10.99(1,30), .002 \\
\mathrm{~T} 1>\mathrm{T} 4\end{array}$ \\
\hline $\begin{array}{l}\text { Orientation } \\
\text { Positive }\end{array}$ & 1.36 & .08 & N/A & N/A & N/A & N/A & N/A & N/A & N/A & N/A & 1.09 & .03 & .81 & $.30: 1.33$ & $\begin{array}{l}\mathrm{F}=10.50(1,29), .003 \\
\mathrm{~T} 1>\mathrm{T} 4\end{array}$ \\
\hline $\begin{array}{l}\text { Orientation } \\
\text { Negative }\end{array}$ & 1.35 & .08 & N/A & N/A & N/A & N/A & N/A & N/A & N/A & N/A & 1.05 & .03 & .91 & $.38: 1.43$ & $\begin{array}{l}\mathrm{F}=11.06(1,30), .002 \\
\mathrm{~T} 1>\mathrm{T} 4\end{array}$ \\
\hline DCQ & 1.93 & .07 & 1.82 & .09 & -.27 & $-.77: .23$ & 1.04 & .12 & -1.35 & $.80: 1.90$ & .90 & .12 & -1.72 & $1.14: 2.31$ & $\begin{array}{l}\mathrm{F}=9.42(10,22),<.001 \\
\mathrm{~T} 1, \mathrm{~T} 2>\mathrm{T} 3, \mathrm{~T} 4\end{array}$ \\
\hline
\end{tabular}

Note ${ }^{\mathrm{a}}$ indicates estimated mean values; ${ }^{\mathrm{b}}$ indicates data that was transformed ${ }^{\mathrm{b}}$ indicates variables where the covariate age was found to have a significant $p$ value $(<.05)$; ${ }^{c}$ indicates variables where the covariate body mass index (BMI) was found to have a significant $p$ value (<.05); ITT, intent-to-treat; M, Mean; SE, Standard Error; d, within-time Cohen’s d; CI 95\%, 95\% Confidence Intervals; df= degrees of freedom. 
Table 4

Multiple Regression Analyses With DCQ at Follow-Up as Outcome Variable, Covarying for Baseline DCQ and Change in Perfectionism Between Baseline and Follow-Up.

\begin{tabular}{lllllc}
\hline Variables & B & SE & Beta & t & $p$ \\
\hline DCQ at T3 $^{\mathrm{a}}$ & -.12 & .35 & -.07 & -.34 & .73 \\
DCQ at T3 $^{\mathrm{b}}$ & .07 & .29 & .05 & .24 & .81 \\
DCQ at T3 $^{\mathrm{c}}$ & .29 & .28 & .20 & 1.02 & .32 \\
DCQ at T4 $^{\mathrm{a}}$ & -.48 & .31 & -.31 & -1.54 & .14 \\
DCQ at T4 $^{\mathrm{b}}$ & .05 & .28 & .04 & .16 & .87 \\
DCQ at T4 $^{\mathrm{c}}$ & -.04 & .26 & -.03 & -.15 & .88
\end{tabular}

Note. ${ }^{a}$ indicates where the Frost Multidimensional Perfectionism Scale (FMPS) Concern over Mistakes (CM) subscale was entered as the dependent variable; ${ }^{b}$ indicates where the FMPS Doubts about Actions (DA) subscale was entered as the dependent variable; ${ }^{c}$ indicates where the FMPS Personal Standards (PS) subscale was entered as the dependent variable; DCQ at $\mathrm{T} 3=$ DCQ score at the end-of-treatment; DCQ at T4= DCQ score at one-month follow-up; T3= endof-treatment period; $\mathrm{T} 4=$ one-month follow-up period. 


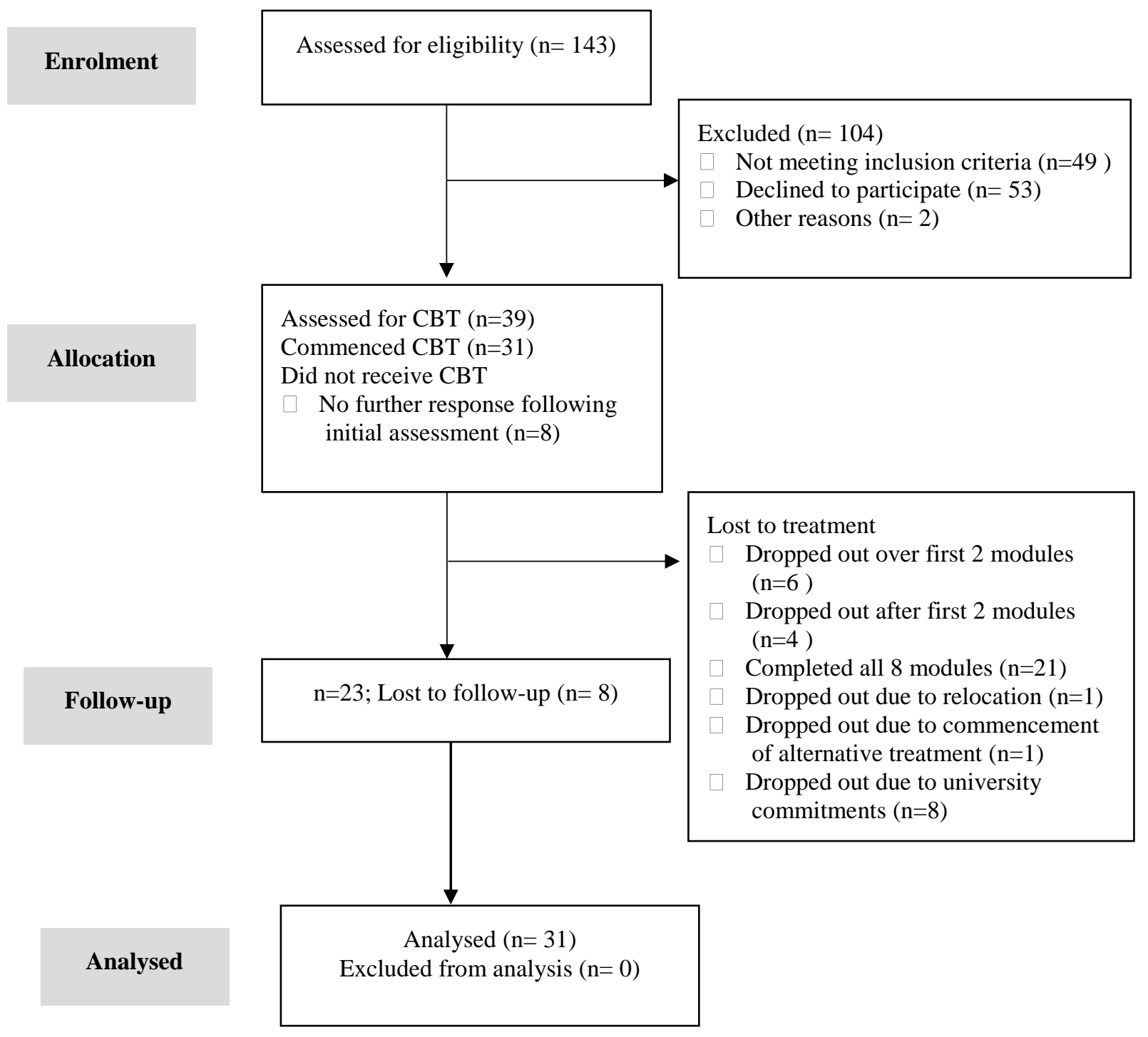

Fig.1. CONSORT flow chart for enrolment, allocation, follow-up, and analysis of participants involved in the online cognitive-behavioural therapy (CBT) for perfectionism program. 


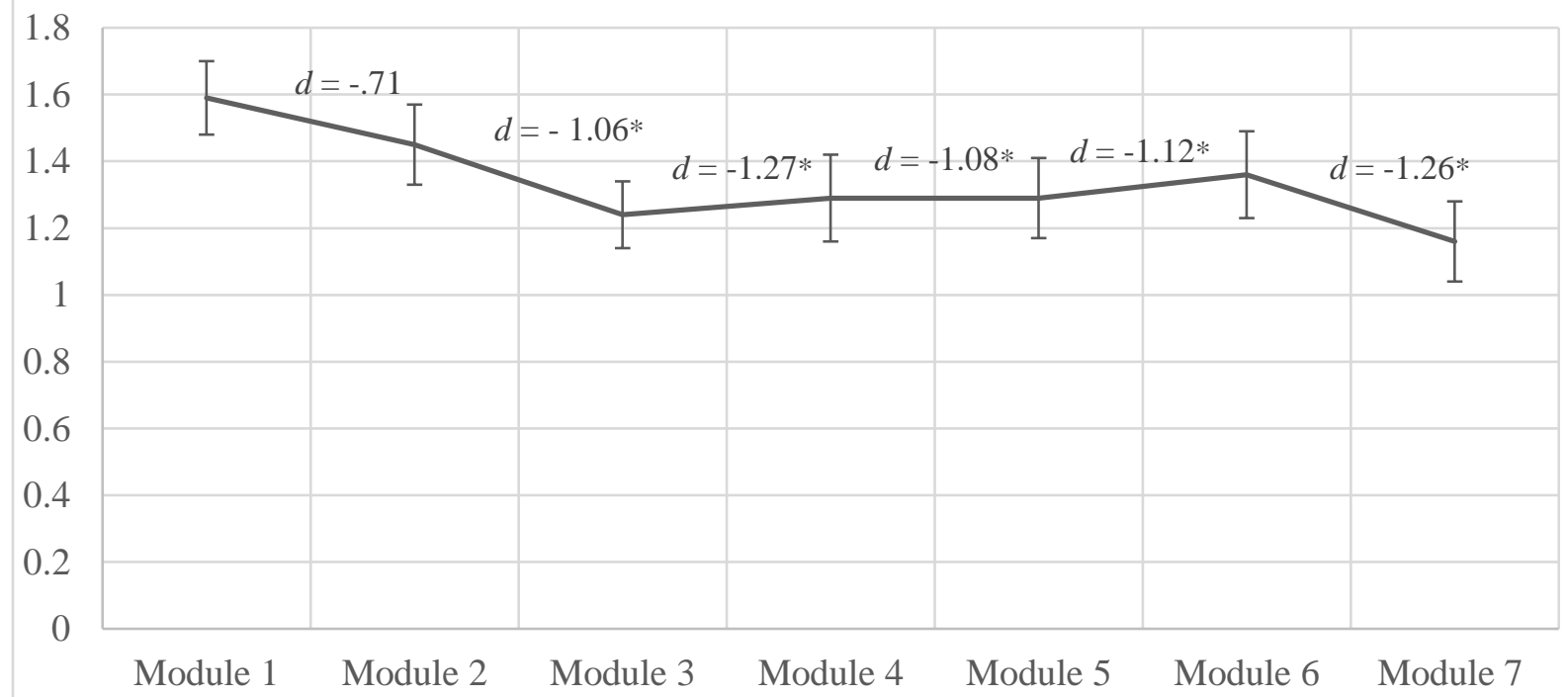

Note. * indicates a significant $d$ value from baseline to post-module completion of the DCQ

Fig.2. Within-group effect sizes (Cohen's $d$ ) between baseline and weekly intent-to-treat (ITT) Dysmorphic Concern Questionnaire (DCQ) scores for modules two to seven. 